\title{
Rethinking European Competition LaW: From a Consumer Welfare to a Capability Approach
}

\author{
Rutger Claassen \& Anna Gerbrandy ${ }^{1}$
}

Abstract: European competition law is predominantly focused on maximizing consumer welfare. This overarching purpose (which is supported by economic theory) leaves little place for safeguarding non-economic values, such as sustainability. This makes it difficult to allow cooperation between companies which contributes to such non-economic goals. In this article we explore whether it is possible to establish a different normative framework, in which such goals can be taken into account and balanced against the economic goal of consumer welfare. To answer this question, we take four steps. First, we discuss (concisely) current EU competition law and the difficulty of fitting noneconomic goals into the dominant interpretation of that law. Second, we proposes a different normative framework, based on the capability approach advanced by philosopher Martha Nussbaum and economist Amartya Sen. Third, we argue that there are good principled reasons to incorporate non-economic goals into competition law. Fourth, we compare to which results applying both the capability approach and the consumer welfare approach to three (illustrative) cases in which noneconomic goals are at stake would lead. Overall, we argue that the capability framework, although not without difficulties of its own, may provide a more legitimate theory for application of European competition law.

\section{Introduction}

To ensure the efficient functioning of markets, European competition law prohibits undertakings from entering into anti-competitive agreements and abusing a dominant position on the market. ${ }^{2}$ It is generally understood that the justification for European competition rules lies in the welfare gains for consumers of having competitive markets. Coordination of behavior between undertakings drives up prices, thus having a negative effect on consumer welfare. Competition law therefore serves to prevent a series of economic benefits (for firms) in order to realize another series of economic benefits (for consumers). However, in quite some situations, companies enter into agreements to further a non-economic goal, such as rendering production facilities more ecologically friendly or strengthening social cohesion in inner city areas. They may have different reasons to do so, but in these cases the question arises: should European competition law take these noneconomic interests into account? If so, how can this be done?

\footnotetext{
${ }^{1}$ Dr. R.J.G. Claassen is associate professor of Political Philosophy at Utrecht University Department of Philosophy. Prof. Dr. A. Gerbrandy is professor of Competition Law at Utrecht University School of Law. This paper was prepared for the Mancept-conference on political philosophy, held at Manchester, October 2014 for the purpose of discussion during that conference.

${ }^{2}$ As is well known, the main provisions of European competition law are articles 101 TFEU (prohibition on anticompetitive agreements (cartels)), and article 102 TFEU (prohibition on abuse of a dominant position). Mergers are subject to an ex ante regime of control as laid down in the merger regulation. Though we focus on agreements that fall within the scope of article 101 TFEU the general line of reasoning may equally apply to article 102 TFEU or to the scrutiny of mergers.
} 
Since the 1990s the European Commission has increasingly adopted a consumer welfare approach to the interpretation of European competition law. In this paradigm, it is hard to give non-economic interests their due, as we will show discussing three recent cases in which economic and non-economic goals clash (section 2). While this 'economic approach' has been criticized, it is a challenge to come up with a constructive alternative. In this article, we propose to use the capability approach as an alternative framework for thinking about competition law. This approach was developed by economist Amartya Sen and philosopher Martha Nussbaum as an alternative to utilitarian approaches in welfare economics and theories of justice. We will introduce the main features of the capability approach and propose how it can be applied to competition law, focusing on two key issues: the identification and the weighing of capabilities in a competition case (section 3). Third, we argue that there are good principled reasons to incorporate non-economic goals into competition law, both in terms of legal interpretation of the relevant EU texts, moral arguments about the appropriate division of labor between private companies and political bodies, and in terms of political considerations about the legitimacy of decision-making by competition authorities (section 4). Fourth, we compare how both the capability approach and the consumer welfare approach would think about the three illustrative cases in which non-economic goals are at stake. We argue that the capability approach better handles these cases (section 5). Overall, the capability framework, although not without difficulties of its own, may provide a more legitimate theory for European competition law.

The method used is multidisciplinary: we combine law with political philosophy (and we are a lawyer with philosophical leanings and a philosopher with a legal background respectively). The aim of our endeavor is to show how theory from political philosophy can show a way out of one of challenges in European competition law. We link this theoretical exploration with practice and show how combining the capability approach with actual competition cases might lead to quite surprising results.

\section{Approaches in EU Competition Law}

The general aim of competition law, as understood by economist and lawyers alike, is to address the market failure of market power by adding a layer of legal rules to ensure the proper functioning of markets. Though the notion that competition is a cornerstone of market economies is widely accepted, there is no agreement on the more specific aims of competition law. In the European context it has always been understood that perfect competition is an ideal, unreachable in practice. However, there are important unresolved questions about the extent to which unfettered competition may be checked by other public policy interests. Especially outside fairly straightforward cases there is no clear-cut answer as to which standard should then be used and positions of Commission and Court, especially where public interest are involved, seem to diverge. 
For our purposes a simple sketch of this debate suffices. Dominant in European competition law currently is the consumer welfare approach, especially since it is advocated by the Commission. ${ }^{3}$ Shortly put, this approach focuses on the outcomes of market exchanges, and does so by considering the value of these outcomes for consumers. Though the concept of consumer welfare itself is not clearly defined, ${ }^{4}$ it is understood through economic efficiencies. ${ }^{5}$ Economists (and lawyers following their lead) will calculate the loss of consumer welfare and the consumer welfare gains. ${ }^{6}$ Both are expressed in the same monetary units, leading to a simple sum: if costs are greater than benefits, the agreement is contrary to competition law.

Under what could be termed a narrow consumer welfare approach, agreements between undertakings leading to an increase in price, a limitation in output (quantity, quality or assortment) or a limitation of innovation, are prohibited as detrimental to consumer welfare. Other interests are assumed to lie outside its scope, thus showing the tension between unfettered competition and other public values. ${ }^{7}$ Here, we use the terminology of 'economic interests' (the consumer welfare interests that are the focus of the narrow consumer welfare approach) and 'non-economic interests' (that fall beyond the scope of assessment in this approach) to connote the difference between these values. Though the boundaries between the two are fuzzy - as our examples below will illustrate - it is generally understood that non-economic interests are benefits that are either not directly included in the consumer-welfare standard, or are not (reliably) economically calculable and thus non-comparable.

However, the broad consumer welfare standard is somewhat more open to include non-economic interests. Such a standard will incorporate (easily) calculable non-economic benefits that are not directly related to the product in question but that do accrue to the

\footnotetext{
${ }^{3}$ Other standards, e.g. concerned with market-structure or processes may also play a role (see e.g. Case C8/08, 4 June 2009, T-Mobile Netherlands and Others, ECR 2009, p. I-4529 and A. Gerbrandy, Case Note to Case C-8/08, T-Mobile e.a.", CMLRev 2010, 47, p. 1199-1220), but the current enforcement focus centres around consumer welfare. The market-structure standard uses legal analysis to balance the interests involved, and though it ties to the ordo-liberal tradition of European competition law, it is fairly ill-defined.

${ }^{4}$ K.J. Cseres, "The Controversies of the Consumer Welfare Standard", The Competition Law Review 3 (2) 2007, p. 121-73.

5 Following from European Commission, Guidelines on the Application of Article 81(3) of the Treaty, OJ EU 2004, C 101/97; European Commission, Guidelines on Vertical Restraints, OJ EU 2010, C 130/1; see also B. Baarsma, "Rewriting European Competition Law from an Economic Perspective", European Competition Journal 7 (3) 2011, p. 559-85.

${ }^{6}$ A legal barrier to apply this 'weighing' to some agreements, however, lies in the text of Article 101 (1) TFEU: for 'object-restrictions', connoting classic cartel arrangements such as price-fixing or restrictions of production, negative effects are assumed and weighing of possible benefits is generally impossible.

${ }^{7}$ T. Prosser, The Limits of Competition Law. Markets and Public Services, 2005, Oxford: Oxford University Press; D. Zimmer (ed), The Goals of Competition Law, 2012 Cheltenham: Edward Elgar; O. Budzinski, "Monoculture versus Diversity in Competition Economics." Cambridge Journal of Economics 32 (2) 2008, p. 295-324; C. Townley, "Is Anything More Important than Consumer Welfare (in Article $81 \mathrm{ERC}$ )? Reflections of a Community Lawyer", 2008 Cambridge Yearbook of European Legal Studies 10, p. 345-81; C. Townley, Article 81 EC and Competition Law, 2009 Oxford/Portland: Hart Publishing; A. Gerbrandy, "Competition Law for a Sustainable Society: Government Action or Private Initiatives in Reaction to Science's Call for Sustainability", in: Law and Governance. Beyond the Public - Private Law Divide?, edited by A.C. Ciachhi, R. Neerhof, M. Heldeweg, and B. van der Meulen, 2013 Den Haag: Boom Juridische Uitgevers.
} 
consumers of these products. Thus it includes these non-economic benefits indirectly, to the extent that they pertain to the same group of consumers as the ones suffering price increases. The example of the Energy Agreement, below, will illustrate such an approach in practice. However, it is unclear just how far these benefits need to relate to the same group of consumers, on the same market. Clearly the further this is stretched, the more controversial the interpretation of the consumer-welfare standard becomes.

As alternative to the consumer welfare approach an inclusive welfare standard (the label is ours) to competition law could be contemplated. ${ }^{8}$ In contrast to the consumer welfare approaches, such an approach takes non-economic interests directly into account, and does not require a link to the same group of consumers. It does so by using a broader conception of 'welfare' and adding (measured and quantified) non-economic benefits to the assessment-mix. Such a standard is based on the idea that anything can be expressed in terms of preferences and thus be quantified and compared, ${ }^{9}$ by asking about consumers' preferences and using a willingness-to-pay quantification in monetary terms. ${ }^{10}$ This does not answer the question of whether one should do so, ${ }^{11}$ and though this standard does include non-economic interests, it does so by using a market-based concept (subjective preference satisfaction) as its starting point. While such a principled decision to include non-economic interests can be applauded from the point of view of safeguarding these interests (see section 4), it is our contention that to take full account of the value of public interests when assessing agreements between companies taking responsibility for public interests, we would need to go beyond such an inclusive welfare standard and introduce a non-welfare standard, such as the one offered by the capability approach. But this is running ahead of the argument. We will first illustrate the difficulties of these approaches, by introducing several competition law cases. In each of these cases non-economic interests present a problem for competition law, and the question is if and how to take these into account. These illustrations will come back in section 5, where we will further discuss the application of the different standards.

A first illustrative case relates to the Dutch Energy-agreement, an agreement brokered in typical Dutch polder-fashion concerning a roadmap towards more sustainable energy in the Netherlands in 2020. Parties to the agreement include energy-producers, distributors, the Government, and Advisory bodies to the Government (Social Economic Council). They agreed to the (accelerated) closing down of five coal-fired power plants, which leads to less supply of electricity and to lower emissions of noxious gases and particulate matter. It is on this element of the agreement - in isolation - that the Dutch

\footnotetext{
${ }^{8}$ Due to the wording of Article 101 (3) TFEU, where a 'benefit to consumers' is explicitly mentioned as a necessary condition for balancing, a total welfare standard is not imaginable in European competition law.

9 C. Rose, "Environmental Faust Succumbs to Temptations of Economic Mephistopheles, Or, Value by Any Other Name Is Preference", Michigan Law Review 1989, 87, p. 1631-1711.

${ }^{10}$ M. Adler, "Welfare Polls: A Synthesis", New York University Law Review 2006, 81 (6).

11 D. Lewinsohn-Zamir, "Consumer Preferences, Citizen Preferences, and the Provision of Public Goods", The Yale Law Journal 1998, 108, p. 377-406.
} 
competition authority ACM provided an 'informal opinion' (a non-binding preliminary assessment), applying (also) European competition law. The ACM labelled the closing of coal-fired power plants a restrictive production-agreement in violation of competition law. ${ }^{12}$

The second case relates to animal welfare, generally labelled a non-economic interest. Under ongoing consideration is an agreement relating to intensive pig-farming (the Verbond van Den Bosch). Parties to the agreement include the provincial government, farmers, animal-fodder producers, veterinarians, and supermarkets. This agreement includes lowering the use of antibiotics in animal husbandry, which results in less resistance to antibiotics in humans and provides for greater animal welfare. But it might also lead to higher consumer prices. In this case there are both human health (i.e. consumer welfare) and animal welfare benefits, so that a broad consumer approach might give some consideration to the benefits of the agreement. But we can easily imagine cases where there are only animal welfare benefits. For example, think of protecting the habitat of a species of birds not even on the brink of extinction. Suppose that dairy farmers, using their grass land for grazing cattle, in collaboration with nature conservation societies, come to an agreement to protect the black-tailed godwit (a protected species). Though not specifically beautiful, it makes an impressive melancholy sound, especially in flocks; but it nor its eggs are generally used as food. The result of such an agreement might be higher prices of dairy products, but also the flourishing of the black-tailed godwit. ${ }^{13}$ How to decide such a case?

A third case interesting to our discussion of the capability approach in competition law concerns efforts to combat binge-drinking (in the UK and Ireland). This phenomenon has become more widespread since the price for alcoholic drinks has decreased relative to other consumptions. Supermarkets were urged to take responsibility for counteracting bingedrinking, which brings with it health risks for young people especially, but also entails health care costs and police effort. However, they are 'trapped in a downwards spiral of pricecentric competition'. ${ }^{14}$ Therefore an important chain of supermarkets in the UK - Tesco proposed to actually reconsider pricing, but only together with its competitors. This pricingagreement would clearly go against competition law, at least if the possible benefits (avoided health care costs, lower policing costs, and better inner-city atmosphere and livability) are not taken into the assessment. Legislative action was then considered, by setting a minimum price for alcoholic beverages. ${ }^{15}$

In all of these cases it is difficult to take non-economic interests into account in a systematic way, if a consumer welfare standard is used, as will be further discussed in section 4 . It is for this reason that we propose an alternative approach, which will be

12 Autoriteit Consument \& Markt, Notitie ACM Sluiting Kolencentrales, 2013, at: https://www.acm.nl/nl/publicaties/publicatie/12033/Notitie-ACM-over-Sluiting-5-Kolencentrales-in-SEREnergieakkoord.

${ }^{13}$ See: 'Boerengilde kansrijker dan biologisch', Leeuwarder Courant, 15 February 2014.

14 Townley 2008, at p. 348.

15 See: http://www.theguardian.com/society/2012/mar/23/coalition-minimum-alcohol-price-40p and the Update of the House of Commons (SN/HA/5021), of 16 May 2014, available at: www.parliament.uk/briefingpapers/sn05021.pdf. 
introduced first (section3), before discussing what it might mean to use this approach in competition law cases.

\section{A Capability Approach to Competition Law}

\subsection{The Capability Approach as alternative to resourcist and utility approaches}

The capability approach has been developed originally by economist Amartya Sen and philosopher Martha Nussbaum. The capability approach is a flexible framework, which has been used in a variety of contexts. Sen's aim was to propose an alternative view of welfare, compared to standard welfare economics, which is based on the moral philosophy of utilitarianism. ${ }^{16}$ Nussbaum's aim was to propose an alternative to utilitarian and resourcist theories in the area of theorizing about distributive justice. ${ }^{17}$ The common basic idea is that reasoning should start from the fact that individuals have 'capabilities to function' in a specific way. A function or functioning is a 'being or doing' of a person. Eating, sleeping, driving, walking, being healthy, being educated etc. are examples of functionings. A capability is an ability or opportunity to function in a certain way. I have the capability to be well-nourished if I have the opportunity (given my income and access to food markets) to consume a nutritious diet. I may decide not to use my capability; I may choose not to eat today but to fast. But, as Sen has often argued, having such a personal choice is important. A fasting person, but not a starving person, has the opportunity of getting a sufficient nutritional intake. He has the freedom to choose how to function. We can then evaluate the level of welfare or the justice of a society by looking at how well it succeeds in guaranteeing each citizen a set of basic capabilities.

This perspective differs from its competitors, resourcism and utilitarianism. Resources are inputs of any person's capability set. We need food to have the capability to eat, we need health care services to have the capability to be healthy. Resourcist theories define welfare or justice by looking at each person's basket of resources. On a macro-level, evaluating countries' performance by looking at the average resource bundle per person (GDP per capita) is an example of a resourcist approach. However, resources do not translate into capabilities in a straightforward manner. Two persons, one healthy and the other disabled, may need to receive different resource bundles to reach the same set of capabilities, given differential personal, social and environmental conversion factors. Therefore it is important to evaluate economic processes by looking at the actual set of

\footnotetext{
${ }^{16}$ A. Sen, Commodities and Capabilities, 1985 Oxford: Oxford University Press; A. Sen, The Standard of Living, 1987 Cambridge: Cambridge University Press.

17 M. Nussbaum, "Nature, Function, and Capability: Aristotle on Political Distribution", Oxford Studies in Ancient Philosophy, 1988 Supplementary Volume I, p. 145-84; M. Nussbaum, "Aristotelian Social Democracy", in: Liberalism and the Good, edited by R. Bruce Douglas, Gerald M. Mara, and Henry S. Richardson, 1990 New York: Routledge, p. 203-52. The approach has also been used in development studies and quality of life studies (see: I. Robeyns, "The Capability Approach: A Theoretical Survey" Journal of Human Development 2005, 6 (1), p. 93-117; I. Robeyns, "The Capability Approach in Practice" Journal of Political Philosophy 2006, 14 (3), p. 351-76). The United Nations Development Programme (UNDP) has also used the capability approach to rank countries in a Human Development Index which is an alternative to standard GDP-rankings.
} 
functionings individuals are able to realize (i.e. their capability set), instead of merely at their resource input. ${ }^{18}$ On the other end of the process, individuals derive a certain utility or well-being from their functionings. However, here too there is no one-to-one correspondence between a capability set and one's utility level. Two persons with the same capabilities can experience different levels of well-being. If social policy focuses on utility levels, then it will be held hostage by persons who need champaign and caviar to reach the same level of well-being as their neighbors who are content to have fish and chips; or it can miss the urgency of poverty where people have adjusted their expectations and are happy to live on a low level of functionings achievement. The capability approach avoids these opposite pitfalls, ignores both resource inputs and utility outputs and steers our evaluations to the capabilities people actually have.

Sen and Nussbaum have also stressed that the capability approach can be seen as a human rights approach. People should have rights to basic human capabilities. ${ }^{19}$ States are made responsible for the capability level of their citizens. This provides an important connection to the field of law, including competition law.

\subsection{The Capability Approach in the context of Competition Llaw}

For the connection between law and the capability approach to work, two important issues need resolution. First, which capabilities are the basic capabilities that people should have a right to? Sen and Nussbaum have given different answers, where Nussbaum has formulated a list of ten central capabilities, ${ }^{20}$ and Sen thinks this selection process is best left to democratic processes. ${ }^{21}$ Second, how to weigh them against each other and make tradeoffs? These two questions, as to selection and weighing of capabilities are still very much open to interpretation and further development in the capability approach. They are also key to the application of the approach to competition law which means that the difficulties of the capability approach will also be present when using it in a competition law context. ${ }^{22}$

\footnotetext{
${ }^{18}$ H. Brighouse and I. Robeyns (eds.), Measuring Justice: Primary Goods and Capabilities, 2010 Cambridge: Cambridge University Press.

19 M. Nussbaum, "Capabilities and Human Rights”, Fordham Law Review 1997, 66, p. 273-300; A. Sen, "Elements of a Theory of Human Rights", Philosophy \& Public Affairs 2004, 32 (4), p. 315-56.

${ }^{20}$ M. Nussbaum, Women and Human Development. The Capabilities Approach, 2000 Cambridge: Cambridge University Press.

${ }^{21}$ A. Sen, The Idea of Justice, 2009 Cambridge, Massachusetts: The Belknap Press.

${ }^{22}$ There have not been many applications of the capability approach to law. Exceptions include work on property law (see: G. Alexander, "The Social-Obligation Norm in American Property Law", Cornell Law Review 2009, 94 (4), p. 745-819; G. Alexander, "The Complex Core of Property", Cornell Law Review 2009, 94 (4), p. 1063-71; G. Alexander and E. Penalver, An Introduction to Property Theory, 2012 Cambridge: Cambridge University Press), on contract law (see S. Deakin, “'Capacitas': Contract Law and the Institutional Preconditions of a Market Economy", European Review of Contract Law 2006, 2 (3), p. 317-41; M. Hesselink, "Capacity and Capability in European Contract Law", European Review of Contract Law 2007, 3 (15), p. 323-48) and social rights (see S. Deakin and J. Browne, "Social Rights and Market Order: Adapting the Capability Approach", in: Economic and Social Rights under the EU Charter of Fundamental Rights - A Legal Perspective, edited by Tamara Hervey and Jeff Kenner, 2003 Portland, Oregon: Hart Publishing, p. 27-43.
} 
As a necessary first step, therefore, all the capability interests of the parties that have a stake in competition disputes need to be identified. To tailor the approach to the competition law context we propose to conceptualize these as consisting of three distinct types of capability sets: market-constituting capabilities, consumptive capabilities and thirdparty-capabilities.

First, market-constituting capabilities, we submit, would consist of the capabilities to hold property and to contract, i.e. the ability to engage in voluntary exchanges with producers to obtain goods and services. These capabilities are constitutive for the institution of the market in the sense that the market could not exist without them. ${ }^{23}$ The capability approach can and arguably should recognize the two basic market freedoms - to hold property and to contract - as important capabilities that are valuable for citizens to possess. ${ }^{24}$ These capabilities, then, express the value of freedom of choice in the economic context. $^{25}$ This does not mean that the capability approach is fanatically pro-market, because as we will see the approach will also recognize other valuable capabilities, which need to be weighed against each other, but nor is it anti-market. ${ }^{26}$ In a competition case, these market-constituting capabilities have weight because they express the producers' freedoms to conclude agreements with each other as they see fit. These freedoms may obviously come into conflict with the two other sets of capabilities, to which we now turn.

Second, consumptive capabilities refer to a set of widely different basic capabilities that are essential to human flourishing: capabilities to health, education, nourishment, housing etc. These are called consumptive capabilities because each of these capabilities in turn requires (amongst other things) consumers' ability to purchase those goods and services which are necessary to realize them. The market is instrumental to the production and exchange of these goods: it may, or may not, be the best institution to achieve them. From a capability perspective, given the scarcity of resources, the most efficient system of providing these goods should be chosen, so that the total set of capabilities can be realized at least up to a threshold level. ${ }^{27}$ In competition cases, this means that consumers' interest in consumptive capabilities (say, to heating houses and cooking food) translate into an interest in getting market goods (say, gas and electricity) delivered to them the lowest possible price; given the fact that this will leave them with as much budget as possible to satisfy their other basic capabilities (later in this section this claim will be qualified).

Third, we propose to use the label of third-party capabilities to refer to capabilities of others than consumers or producers. Here non-economic interests enter the capability

\footnotetext{
${ }^{23}$ Deakin and Browne 2003.

${ }^{24}$ R.J.C. Claassen, "The Capability to Hold Property", Journal of Human Development and Capabilities 2014 (accepted, forthcoming).

${ }^{25}$ Nussbaum does not mention this capability explicitly, but she does include a capability of "being able to hold property' on her list of basic capabilities (Nussbaum 2000, at p. 80).

${ }^{26}$ The capability approach will assess the legitimacy of specific markets on a case-by-case basis: R.J.C. Claassen, "Institutional Pluralism and the Limits of the Market", Politics, Philosophy, and Economics 2009, 8 (4), p. 42047.

${ }^{27}$ Note that the efficiency-arguments in favor of markets which are familiar in a standard economic framework are translated into the capability framework here (see also Claassen 2014).
} 
approach. In the Dutch energy agreement, for example, these are capabilities of future generations - Sen has argued that we do indeed need to take into account future generations ${ }^{28}$ - which stand to be harmed from damage to the climate if $\mathrm{CO}_{2}$-emissions aren't reduced in time. ${ }^{29}$ In the case about intensive pig farming animal capabilities are at stake; Nussbaum has argued that animals have rights to capabilities to a minimally flourishing life as well. ${ }^{30}$ In the case of binge-drinking we need to deal with capabilities to health of (a.o.) young people, as well as capabilities to security of inner-city inhabitants. These examples are not exhaustive: there is a wide variety of third-party capabilities. Now, we do not claim that it is uncontroversial that these third-party capabilities should be recognized. But we do argue that competition law should make room to discuss and possibly incorporate non-economic interests (section 4) and show how this can be done when one would conceptualize these interests in terms of capabilities (section 5).

The second step in the application of the capability approach to competition law is to weigh the capability interests at stake. There are three issues at stake here.

A first issue is how much weight every capability should get. Capabilities cannot be weighed using market prices because these rely on each individual's purchasing power and willingness to pay. Imagine two different cases. In case $X$ the animal capabilities of a group of chimpanzees must be weighed against consumers' capability to purchase life-saving health care medication, while in case $Y$ the same animal capabilities must be weighed against the consumptive capabilities to purchase a new brand of cosmetics. Quite apart from the size of the respective groups (suppose the numbers of animals and consumers are the same across $X$ and $Y$ ), the value of the consumptive capability will be different in a different product market. This is an important area of difference with an economic approach, which simply counts preferences and is methodologically blind to the different social weight of different capabilities. This means we need alternative ways to establish weights. In the end, whatever methodology we choose, the actual weighing process needs to be done in an institutional context that is democratically legitimated (see section 4).

A second issue is the distributive principle guiding such a weighing exercise. The analogy with economic reasoning suggests to maximize the total level of capabilities. Let's assume that in a competition case there are four parties, A \& B (producers) and C \& $D$ (consumers). Assume that if we allow an agreement between $A \& B$ to stand this raises their capability levels to 15 , while $C \&$ D's capability levels fall to 10 . In the situation where the agreement is prohibited as a violation of competition law, A \& B will experience a capability level of 5 , and $C \& D$ of 25 . The second situation, then, realizes a higher total capability level (30), compared to the first situation (25). However, as Nussbaum proposed each basic capability should be realized up to a threshold level. If the threshold would be put at, say, 8 ,

\footnotetext{
${ }^{28}$ S. Anand and A. Sen, "Human Development and Economic Sustainability", World Development 2000, 28 (12), p. 2029-49.

${ }^{29}$ S. Caney, "Climate Change, Human Rights and Moral Thresholds", in Human Rights and Climate Change, edited by Stephen Humphreys, 2009 Cambridge: Cambridge University Press.

30 M. Nussbaum, Frontiers of Justice, 2006 Cambridge, Massachusetts: The Belknap Press.
} 
then the second situation is problematic because it allows the capability level of A \& B to fall below the threshold. Using this principle means opting for situation $A$, where all parties' capabilities are above the threshold. This threshold principle would be important in competition cases as well, as we will show, and holds that it is more important for each person to have a sufficient level of every basic capability, than to have a maximal aggregate level. For example, the value of the capability to contract is that it allows freedom of choice. The capability to contract is more meaningfully realized to the extent that consumers are able to choose from a larger variety of contract partners. Other things being equal, a choice is more meaningful when there are more alternatives to choose from ("your money or your life!" is not an attractive choice situation to be in). However, at some point, there are diminishing returns. To be able to choose from 50 brands of washing powder arguably is not much more valuable than to be able to choose amongst 30 brands.

Other basic capabilities exhibit a similar structure of diminishing returns. Most pertinent in the competition context is that thinking in terms of thresholds is antithetical to the economic end of maximizing consumptive capabilities (and the accompanying effort of competition authorities to ensure the lowest possible price on the market). When the budget of consumers is sufficient to satisfy all their basic consumptive capabilities then any further protection of consumptive capabilities only works to bring them even higher above the threshold than they already are. ${ }^{31}$ Such increases above the threshold are less valuable than increases to bring them up to the threshold level. When a price-increasing producer agreement serves to protect third-party capabilities (which we imagine have not yet reached the threshold) and thereby increases prices so that it decreases consumer capabilities (but still keeps them above the threshold), then the first may weigh heavier than the latter.

A final issue is whether the weighing act should take a quantitative form (call this type of weighing 'calculation'), on the model of an economic cost-benefit analysis, or a qualitative form (call this type of weighing 'balancing'). Some authors argue that capabilities can be measured. ${ }^{32}$ If that is the case, then there are no principled objections to a quasieconomic weighing of capabilities. Other authors, however, follow Nussbaum in stressing the incommensurability of capabilities: each of them is of separate value and these values cannot be compared in terms of a common metric. ${ }^{33}$ In the absence of commensurability, we can make choices, but these take the form of a discursive style of reasoning in which different types of interests are roughly balanced against each other. This type of balancing is also familiar in the legal literature. ${ }^{34}$ Our line on this is that we should proceed with care

\footnotetext{
${ }^{31}$ This may be the case for citizens in rich and sufficiently egalitarian countries. Any criticism that a price increase makes some groups unable to satisfy their basic capabilities, can also be resolved by general redistribution - it does not necessitate prohibiting the price increase.

${ }^{32}$ S. Anand and M. van Hees, "Capabilities and Achievements: An Empirical Study", Journal of Socio-Economics 2006, 35, p. 268-84; S. Anand, G. Hunter, I. Carter and K.Dowding, "The Development of Capability Indicators", Journal of Human Development and Capabilities 2009, 10 (1), p.125-52.

${ }^{33}$ Nussbaum 2006, at p. 85.

${ }^{34}$ R. Alexy, “On Balancing and Subsumption. A Structural Comparison”, Ratio Juris 2003, 16 (4), p. 433-49.
} 
when we try to quantify non-economic interests. It may be possible to quantify where we mainly need to balance price-related consumptive capabilities to price-related marketconstituting capabilities. But when non-economic interests come into the picture, quantifying would often distort the nature or magnitude of the interests at stake.

\section{The argument for inclusion of non-economic interest in competition law}

As the cases above illustrate, undertakings, sometimes co-jointly with pressure-groups and/or governmental bodies, may decide to take responsibility for a public interest and join forces in improving (parts of) their processes. These initiatives have in common that market agents take responsibility for a public interest, be it a transition towards a sustainable society, taking a place in "Big Society" or some other goal. Of course, such initiatives generally will not be against the self-interest of the companies concerned either, resulting in good public relations, a well-known and outstanding reputation or profit in a new market. In competition law this type of agreements and cooperation sits at odds with the competition law paradigm of individual agents, seeking self-interested profit-maximization. In the discussion on the goals of competition law and standards to be used in assessing competition cases, arguments have been made against incorporating non-economic interests in a competition law assessment. We will review three main arguments, which we have labelled the legal, moral and political argument. We will reject each of them.

First, some do argue that the relevant legal texts do not support inclusion of noneconomic interests in a competition law assessment; though often this argument is enmeshed in the moral argument, presented next. ${ }^{35}$ In the European context these texts are the Treaty on the Functioning of the European Union, secondary legislation and policydocuments of the Commission. The reason to focus on consumer welfare is, firstly, because the exception of Article 101 (3) TFEU includes the requirement of a fair share of benefits accruing to consumers. Secondly, because in secondary legislation and accompanying guidance the Commission focuses on consumer welfare, ${ }^{36}$ and because the Commission is an important actor in shaping and enforcing competition law, these latter documents carry legal and interpretational weight. ${ }^{37}$ Others, however, have argued that these texts leave room for, or even require, a broader interpretation. They ultimately agree that a coherent reading of the Treaty provisions, including its general goals, ${ }^{38}$ and its integration clauses, ${ }^{39}$

\footnotetext{
35 M. Motta, Competition Policy: Theory and Practice, 2004 Cambridge: Cambridge University Press; O. Odudu, The Boundaries of EC Competition Law: The Scope of Article 101, 2006 Oxford: Oxford University Press.

${ }^{36}$ European Commission, Guidelines on the Application of Article 81(3) of the Treaty, OJ EU 2004, C 101/97; European Commission, Guidelines on Vertical Restraints, OJ EU 2010, C 130/1.

37 For a discussion also: Townley 2008; I. Lioanos, "Some Reflections on the Question of the Goals of EU Competition Law", CLES Working Paper Series 3/2013, at p. 15.

${ }^{38}$ Article 3 of the TEU includes references to 'sustainable development', 'balanced economic growth' and a 'social market economy'.

39 Integration clauses are included in the Treaty and link general policy-aims, such as protection of culture or the environment, with all other policy-domains, including competition policy. See specifically in relation to
} 
lead not to any single goal (and thus: standard) of competition law. Instead, they argue, several, sometimes conflicting, goals are possible, and indeed present in the interpretation of the competition law provisions by the Court. ${ }^{40}$ We agree with the latter authors. There seem to be no convincing legal reason for not incorporating non-economic interest into competition law. ${ }^{41}$

Second, there is the moral argument that private parties should concentrate on the market-internal end of profit-maximization and not try to realize social ends that lie outside the market. This argument presupposes a particular division of labour between the private and the public realm. Private actors concentrate on their private ends, and in doing so ensure the optimal functioning of the market mechanism. Public actors legislate in favour of public ends, and in doing so ensure a level playing field of publicly defined constraints under which market agents pursue their own interests. This argument, then, rests on two related grounds. On the one hand, it is concerned with the optimal economic functioning of the market, in terms of consumer preferences. Collusive agreements between private actors are a threat to this and competition law aims to restore the market's functioning by prohibiting them where they distort competition. On the other hand, the argument is concerned with the coherence of different parts of the legal system. Competition law has a different function from other areas of law. Whereas other areas may constrain market actors in order to realize non-economic ends, competition law constrains market actors to make the market function on economic terms. Thus, competition law should not be overburdened and made incoherent by also having to deal with these non-economic ends. ${ }^{42}$

The reason for calling this a 'moral' argument is that the upshot of this division of labor between private and public actors (and between different parts of the legal system) is that market actors cannot assume their moral responsibility in the same way in which this is possible for private persons operating outside of a market context. A group of producers who believe it is their moral responsibility to tackle - as a group - a social problem is unable to do so because they are declared part of a system which is only geared towards one goal, consumer welfare. In the field of business ethics, this position - that firms do not have a moral responsibility - is very controversial, to say the least. Most authors there argue that firms do have a moral responsibility, although of course the exact ground on which this is argued, as well as the scope of these obligations, are in much debate. ${ }^{43}$ The capability

\footnotetext{
competition law and environmental protection: S. Kingston "Integration Environmental Protection and EU Competition Law: Why Competition Isn't Special." European Law Journal 2010, 16 (6), p. 780-805.

${ }^{40}$ Lianos 2013; Townley 2008.

${ }^{41}$ We believe this position also fits the stance of the capability approach, although it is not dictated by it. Nussbaum has argued that the capability approach represents a distinct method of judicial interpretation, which pays attention to the social and historical context of cases, and stands in contrast to more formalist method of interpretation (see M. Nussbaum, “Constitutions and Capabilities: 'Perception' against Lofty Formalism", Harvard Law Review 2007, 121 (4), p. 4-97).

${ }^{42}$ Baarsma 2011 (at p. 585) for example, states that 'Competition law is only intended to solve problems concerning market power (...). The government must resolve different market failures using different policies'.

${ }^{43}$ E. Garriga and D. Mele, "Corporate Social Responsibility Theories: Mapping the Territory", Journal of Business Ethics 2004, 53, p. 51-71.
} 
approach has been used to this extent as well. ${ }^{44}$ One important reason for assuming moral responsibility is that legislators are often too slow or at too far a distance from practice to do be able to effectively regulate social problems. ${ }^{45}$ The emergence of movements for corporate social responsibility in the last decades can be interpreted as a sign that the cooperation and initiative of private actors are necessary in an era of declining public capacity to tackle problems effectively. To prohibit agreements to reach non-economic goals would mean to drain private actors' responsibility for them.

Perhaps the real reason behind the reluctance to grant moral responsibility to private actors lies elsewhere: at the consequences this would have for the authorities having to evaluate these private actions when being called upon to settles disputes in the context of competition law. This brings us to the third and political argument: that a weighing of such different interests - a market interest against a non-market interest - does not belong to the legitimate authority of administrative agencies. ${ }^{46}$ Though opinions on the strength of the legal basis differ, this legitimacy-argument is serious: it holds that it is exclusively for democratically elected parliaments to pass legislation that would close down coal fire power plants, prevent binge-drinking by providing a minimum price, protect animal welfare by providing detailed regulations, or impose on farmers obligations to protect the black-tailed godwit?

In reply we would like to offer two considerations. First, it is no less controversial to give exclusive recognition to economic interests in situations where non-economic interests are also at stake, than to acknowledge both sets of interests. In our view, therefore, it is the legal decisions by competition authorities which exclude non-economic interests which lack legitimacy. For once brought forward by one of the parties in the dispute, it seems arbitrary to exclude non-economic interests to the advantage of the economic interests at stake. In political philosophy, it is widely recognized that only democratic process which include all interests at stake can gain legitimacy. ${ }^{47}$ From this perspective, the political argument must be turned on its head. Moreover, if the weighing of an administrative agency dissatisfies groups of citizens and politicians, then nothing prevents law-making as a way of correcting those judgments and making regulations which express a different weighing of the interests for future cases. The explicit weighing of these interests by a competition authority will serve as a trigger for lawmaking authorities, who can still have the last word on the matter if they want to.

\footnotetext{
${ }^{44}$ A. Bertland, "Virtue Ethics in Business and the Capability Approach", Journal of Business Ethics 2009, 84, p. 25-32; B. Giavanola, "Re-Thinking the Anthropological and Ethical Foundation of Economic and Business: Human Richness and Capability Enhancement", Journal of Business Ethics 2009, 88, p. 431-44.

45 Though the binge-drinking case shows that it is possible, the other cases are illustrations of the government being involved in (brokering) the agreements instead of choosing a legislative route.

${ }^{46}$ At least not without a clear legal mandate, see e.g. T. van Dijk, and P de Bijl "Mededingingsbeleid en Publieke Belangen: Een Economisch Perspectief", Markt \& Mededinging 2012, 4, p. 149-56.

47 A. Gutman and D.Thompson, Democracy and Disagreement, 1996 Cambridge, Massachusetts: Harvard University Press; J. Habermas, Between Facts and Norms. Contributions to a Discourse Theory of Law and Democracy, 1996 Cambridge: Polity Press.
} 
Second, we should not underestimate the potential for democratic elements to be added to the decision-making procedure at the administrative agency itself. For example, the public at large could participate through consultations. But possibly more promising would be to include elements of deliberative democracy, by involving a representative group of the public in the decision-making procedure where non-economic interests are raised. In this forum of debate, where all points of view are discussed and weighed on their merits, without the power-base of the discussant being the defining factor of acceptance, ${ }^{48}$ a balancing of interests would be at stake. ${ }^{49}$ This means calling upon the public not as consumers, but also as citizens. ${ }^{50}$

In conclusion, we are not convinced by the arguments raised against including noneconomic interest in a competition law assessment. Which brings us to the next step in our argument: actually applying the capability approach to the cases introduced above in exploration of whether this would constitute a viable alternative to the current approaches to competition law.

\section{Applying the Capability Approach}

It is one thing to argue in general - as we have done in the previous section - that noneconomic goals should be taken into account in competition law. It is quite another thing to show how this can be done. Therefore in this section we will show how the capability approach can be used in competition cases, using the three cases presented in section 2: the Dutch energy agreement, the animal welfare case and the binge drinking case. We will start by discussing these cases under the currently dominant consumer welfare approach, which as we saw does not incorporate non-economic goals (5.1). Then we will show how the capability approach can be applied, by making use of the framework introduced in section 3 (5.2). We will then show the differences between the capability approach and its economic cousin, i.e. the inclusive welfare approach (5.3).

\subsection{Applying the consumer welfare approach}

Above we distinguished two versions of the consumer welfare approach. Under the narrow consumer welfare standard, there is a limit to considerations of the direct effects on the consumers of the product in question, especially the price-effect on consumer welfare. Under this standard all three agreements of our example-cases would be prohibited. As introduced above the Dutch Energy Agreement concerns an agreement between Energy companies and other stakeholders to change towards sustainable energy-production in the Netherlands. A specific agreement to close down noxious coal-fired power plants was included in this overall agreement. Economic theory suggests that taking production out of

\footnotetext{
${ }^{48}$ S. Chambers, "Deliberative Democratic Theory", Annual Review of Political Science 2003, 6, p. 307-26.

49 As brought forward by Gerbrandy 2015, European Law Review (accepted, forthcoming).

${ }^{50}$ On the impact of this difference also Lewinsohn-Zamir 1998-1999.
} 
the market will lead to an increased price (because of the decrease in supply). ${ }^{51}$ Similarly, in the animal welfare cases higher production costs lead to an increased price of pork and an increase in the price of dairy products as a result of agreeing to protect the black-tailed godwit. Finally, in the binge-drinking case the agreement on prices of alcoholic beverages between supermarkets will also increase prices. All these agreements therefore lead to lower consumer welfare and thus violate competition law.

Using a broad consumer welfare approach means weighing the negative effects on consumer welfare against quantifiable benefits of these agreements to consumers. For example, the avoided costs of health care of consumers of energy (and also of pork, by ingesting less antibiotics, or alcohol, by drinking less), are calculated and taken into account. These benefits apply to the same group of consumers who suffer from price increases, albeit that the benefits occur on different markets. This approach was actually applied by the Dutch competition agency ACM in the Energy Agreement case. All consumers are affected by an increased price, but all also benefit from avoided health care costs of lower emissions of noxious gases. However, the ACM limited its acknowledgment of the benefits of avoided health care costs to the lowering of the emission of NOx, SOx and particulate matter, and controversially - excluded the lowering of CO2-emissions. ${ }^{52}$ The compounds NOx and SOx play a role in creating harmful particulate matter, smog and acid rain and have an effect on health (esp. on the respiratory system), on visibility, on corrosion (of metals and statues), and on the environment and the eco-system. A lowering of these emissions has both an immediate local effect on health and an immediate and long-term effect on the environment, locally and globally. As for particulate matter, these very small particles contain solids or liquids that can enter the lungs and thus result in serious health problems, as well as leading to environmental damage. Thus a lowering of particulate matter has a direct local effect on health, as well as a more non-local effect on the environment. The ACM calculated the health care benefits of these three types of emissions and weighed it against the welfare loss caused by the agreement (its conclusion was that the latter weighed heavier; thus the agreement was declared in breach of competition law).

The energy case show how the broad consumer welfare approach can take into account non-economic goals, such as health, but only in an indirect way: by calculating

\footnotetext{
${ }^{51}$ Though the parties to the agreement argue that an increase in sustainable energy production and supply, also the result of the Agreement (but not a direct result of the closing of the coal-fired power plants) will balance this effect on supply. This was not taken into account by the competition authority in its preliminary opinion.

${ }^{52}$ Lowering CO2-emissions would normally result in lower health care cost (locally), and abate the greenhouse effect (globally and on the longer term). But because CO2-emission is regulated by the ETS, the ACM argued that any reduction of $\mathrm{CO} 2$ emissions from the closed plants would not necessarily lead to reduction of total CO2 emissions: the ETS is a system of trade of CO2 emissions, in which a cap is set on total EU-emissions. Plants emitting $\mathrm{CO} 2$ have an 'allowance' to do so, which, if not used (or not up to its maximum), can be traded. From the (publicly available) text of the Agreement it is unclear whether the parties intended, or are able to take their resulting allowance off the market completely or to trade this under the ETS. Thus, there may be no effect at all. Of course, if the parties to the Agreement were to signal that the $\mathrm{CO} 2$ emissions would be taken out the ETS altogether, as has been suggested as a possibility, the resulting avoided health-care costs would also have to be taken into account.
} 
avoided health care costs. Similarly, it is possible to present the advantages of preventing binge-drinking as a matter of avoided health-care costs of the youths involved, just as it is possible - though the chain of causality is stretched - to include the notion that using less antibiotics to raise pigs leads to lower human health care costs. However, there is a difference in valuing health in itself, as a capability (as we will show below) and valuing the avoidance of (quantified) health care costs. The limits of the consumer welfare approach become even more apparent in the non-consideration by the ACM of the long-term ecological effects of the Energy Agreement. A greater resilience of the eco-system, for example, cannot be accounted for in terms of avoided health care costs. Furthermore, a consumer welfare standard generally will not consider long-term effects: its horizon is limited to 3 - 5 years.

The consumer welfare standard also falls short when we consider the animal welfare case as there is no consumer welfare effect from increasing an animal's living space or protecting the black-tailed godwit. In the latter case one would need to stretch the notion of consumers to include a market for leisure, where consumers benefit from being able to hear and see different birds when hiking or biking, as these benefits do not necessarily accrue to the same consumers as those paying the higher price (on the dairy consumption market). All of this requires heavy conceptual gymnastics from the consumer welfare approach. Where benefits do not accrue in any straightforward manner to consumers, this standard therefore fails to integrate non-economic goals into a competition law framework.

\subsection{Applying the Capability Approach}

A capability approach would start by taking into account the three groups of capabilities mentioned in section 3. First, consider the market-constituting capabilities of property and contract. The capability to property of the energy production companies relates to their ownership of coal-fired power plants and other production assets. ${ }^{53}$ This capability is in itself not limited by competition law. By contrast, the capability to contract is directly limited by competition law: concluding agreements restricting competition is prohibited. Prohibiting an agreement to close production capacity means limiting the energy-producers' capability to contract. Interestingly, the market structure of this case means that this has a negative impact on the capability to property as well. For in this case there is a 'first mover disadvantage': a change to sustainable production by an individual producer is not feasible, because such a production mode is more expensive, leading to higher prices, so that consumers will switch to the producer offering a lower price for a less sustainable product. It is therefore infeasible for an individual producer to take the lead alone. If the alternative route of collective agreements is prohibited by competition law, then the capability to property is limited as well. More precisely: no capability is left to use one's property to

\footnotetext{
53 The capability to property also concerns the allowances of emissions, but this seems to us a derived capability that is limited by competition law: it is not competition law itself that prohibits individual companies to take their allowances from the ETS. Deciding together to not trade the resulting allowances back into the ETS would make a stronger case for the Energy Agreement from all perspectives, however.
} 
produce in a sustainable manner. In the same vein, the market-constituting capabilities of producers of pork and dairy products, and those of supermarkets fighting binge-drinking are at stake in the other cases.

Both the consumer welfare approach and the inclusive welfare approach do not take into account these capabilities of producers. The capability approach is broader in that it values the freedoms (opportunities) of market participants in a principled way. Markets need to be evaluated both in a non-instrumental, or deontological way and for their instrumental benefits, i.e. in terms of their outcomes. ${ }^{54}$ This non-instrumental valuation of producers' market freedom may be suspicious in the competition context, given its aim to counter producer power to the benefit of consumers. However, in cases where noneconomic interests are involved, it comes to the fore how this focus leads to problems as producer capabilities cannot be taken into account, even where undertakings mean to protect a widely-valued public interest. Of course, this does not mean that marketconstituting capabilities will be the only thing valuable (such as in libertarian approaches which exclusively rely on the value of market freedoms) when using a capability approach. They need to be balanced against the other two classes of capabilities.

Second are consumptive capabilities. In the Energy Agreement case, these are all capabilities to function that need the supply of electricity: cooking, warming, cooling, washing, lighting etc. ${ }^{55}$ As a result of the energy agreement these capabilities are negatively impacted, as the goods necessary to realize them become more expensive. Less total consumption is possible, leading either to less consumption of energy or of other goods. Similarly, in the animal welfare and binge-drinking cases, there are clear consumer capabilities at stake, which are negatively affected by any price increases as a consequence of producer agreements. These consumer interests are also included in the assessments of the consumer welfare and the inclusive welfare approach. For this category, the difference lies elsewhere. Against both other approaches, the capability approach evaluates consumptive capabilities differently once their threshold is reached (see section 4). As long as basic/core capabilities can still be met (are still on a level above this threshold), individuals have sufficient capabilities to (still) flourish. An increase of the price of energy, which does not result in a situation where basic capabilities cannot be met above the threshold, is therefore less problematic from this perspective. If there are weighty (thirdparty) capabilities on the other side of the balance, this might lead one to accept the decrease in consumer capabilities due to price increases. The consumer welfare approaches obviously would not use such a differential value of price increases depending on the remaining budget of consumers. But the capability approach can discriminate between different situations, and take into account that a given price increase for a generally affluent population is not the same thing as the same price increase for a poorer population.

\footnotetext{
${ }^{54}$ A. Sen, "The Moral Standing of the Market", Social Philosophy and Policy 1985, 2 (2), p. 1-19.

${ }^{55}$ Indirectly, also the use of energy by other producers of goods and services, which consumers need for their capabilities are touched: clothing, street lighting, schooling, transport (trains, trams, electric cars), etc.
} 
Finally, third-party capabilities. As mentioned earlier, in this category we find a wide variety of capabilities. In the cases under discussion in this article we find four examples of third-party capabilities: capabilities to health, capabilities of future generations, animal capabilities and citizen capabilities.

First, in most of the cases discussed the capabilities to health of consumers are at stake. In the Energy Agreement case health is negatively affected through emissions, in the animal welfare case through the use of antibiotics, and in the binge-drinking case by drinking too much. In these cases, a broad consumer welfare approach could take health into account by looking at avoided health care costs (as explained above). However, valuing such a capability is very different from valuing the avoidance of (quantified) health care costs. Being of good health is a basic capability to function, which has to be taken into account when applying a capability approach. This capability is affected by lower emissions immediately leading to greater health. Furthermore, as indicated in section 3 , though the set of basic (minimum) capabilities necessary for individuals to flourish may be the same for everyone, the 'amount' of resources needed for reaching a threshold level of the capability to health may differ between persons (interpersonal variability in converting resources into functionings). This suggest that a capability approach to the closing of coal-fired power plants might take into account that the reduction of emissions would lead, for individuals with respiratory problems, to an immediate higher level of functioning, coming over the threshold, even if for others the resulting improvement in health are negligible in this sense.

Second, the capability approach may acknowledge capabilities of future generations. In the Energy Agreement case, this would do justice to the fact that lowering emissions has important effects which go beyond any currently existing base of consumers. A reduction of emissions results in a (better chance of) flourishing of future generations, because of the expected long-term environmental effects. The ETS, of course, restricts the effect of lowering $\mathrm{CO} 2$ emissions, which have a clearly long-term effect on the environment, unless the resulting allowances of $\mathrm{CO} 2$ emissions are not traded back in the system: a capability approach would not change the fact that, as in using an inclusive welfare standard, the case of the producers would be much stronger if this were the case. ${ }^{56}$

Third, in the animal welfare cases, the capability approach might introduce the notion of animal capabilities. Then the capabilities to flourish of the animals involved will have to be balanced against the capabilities of humans, in their roles as producers, consumers and third-parties affected through health impacts. It is widely open to what extent a capability approach should take animal capabilities into account. Nussbaum has argued that we should, ${ }^{57}$ but others have criticized her. ${ }^{58}$ Some have argued that we should

\footnotetext{
${ }^{56}$ A signaling effect might have such an effect though (see note above).

${ }^{57}$ Nussbaum 2006.

58 R. Ilea, "Nussbaum's Capabilities Approach and Nonhuman Animals: Theory and Public Policy", Journal of Social Philosophy 2008, 39 (4), p. 547-63; E. Cripps, "Saving the Polar Bear, Saving the World: Can the Capabilities Approach Do Justice to Humans, Animals and Ecosystems?" Res Publica 2010, 16, p. 1-22.
} 
look at ecosystem capabilities instead. ${ }^{59}$ We cannot conclude this argument here, but argue that the capability approach would give a framework for discussion.

Fourth, in the binge-drinking case there are some citizen capabilities at issue: capabilities of those living in the areas of consumption who are negatively affected by binge-drinking scenes. These might have to be specified as 'capabilities to live in a peaceful neighborhood'. This is a rather individualist interpretation of the problem, which focuses on citizens' being able to live their own lives without being disturbed by noise in the middle of the night, or by excessive pollution on the street. But the case may also be given a more collectivist twist by framing citizen worries about binge-drinking as a concern over social cohesion, or paternalist concerns with respect to the value of the leisure activities of youngsters. Again, we will not take a stance on these issues here, but argue that the capability approach gives reason to coherently discuss these elements in a competition law case.

\subsection{Comparison to an inclusive welfare approach}

With respect to all of these categories, an inclusive welfare approach could also take these non-economic interests into account: it would generally use a willingness-to-pay method. For example, current consumers may be asked how much they are willing to pay (for their electricity today) for a better environment for future generations. Thus, in the Energy Agreement case, consumers would be asked whether they would be willing to pay for the specific higher costs of energy - amounting to 3-4 euro per year per household over 5 years for a (switch to a) sustainable energy production (knowing that these costs are higher than the avoided costs of health-care). ${ }^{60}$ A willingness-to-pay survey could also ask consumers how much they are willing to pay for using less antibiotics in pig-farms and greater animal welfare through providing more spacious living room. It is even possible to use such a method for 'non-use' (for example in keeping the rain forest healthy, knowing one will never travel there), in the case of protecting the black-tailed godwit. If such an inclusive welfare approach can take these interests into account, then the argument can be raised against introducing the capability approach as being superfluous (and stranger to competition law than an inclusive welfare approach).

We do not want to overemphasize our disagreements with the inclusive welfare approach as it does take non-economic interests into account. Nonetheless, there remain important differences with the capability approach to competition law.

A general point is the one which has been important in developing the capability approach as an alternative to preference-based utilitarianism: that preferences may be

\footnotetext{
59 D. Schlosberg, Defining Environmental Justice: Theories, Movements, and Nature, 2007 Oxford: Oxford University Press. However, there might be important tensions here: the survival of ecosystems depends on predator relations which violate individual animals' capabilities to their lives.

${ }^{60}$ It might also make a difference to the consumers whether or not the allowance resulting from the $\mathrm{CO} 2$ emission reduction would be taken out of ETS completely. Even if this were not the case, the consumers might still be willing to pay the higher price, either as a political signal against the ETS and as a minor price to pay for uncertain, but possible, longer-term environmental benefits.
} 
distorted by problematic processes of adaptation and socialization. As a consequence, the answers in willingness-to-pay surveys may have a problematic normative status. If in these surveys no one attaches value to future generations, animals or the health of parts of the population, then these interests do not count. Thus, the protection of these groups would become dependent on the contingent value attached to them in these surveys. This does not do justice to the interests involved. Similarly, the non-welfare value of marketconstituting capabilities (liberties) and the threshold structure of consumptive capabilities will not be taken into account in a robust manner, as long as individuals do not include these in their preferences. To this a defender of the inclusive welfare approach might retort that there is no other basis for making social choices. This is what a defender of the capability approach would deny. Social choices are legitimately made, in the end, in a democratic process. In that process, of course, citizen preferences play a crucial role. But the context of a democratic process is different from the context of a willingness-to-pay survey. The most important difference is that the democratic process is a means to form preferences on the basis of reasons, not to aggregate pre-existing preferences. All the substantive conclusions that we have argued for here, then, should be seen as reasons that may or may not convince co-citizens in a democratic process. Willingness-to-pay surveys do not allow such a process of reasoning to take place, and thus do not allow the subjects that are asked to report their preferences to change them on the basis of new information. ${ }^{61}$ To the extent that an inclusive welfare approach is used by competition authorities to shortcut such a process, this is deeply problematic from a democratic point of view.

\section{Conclusion}

In this article we have argued that there are good reasons to include non-economic interests in a competition law assessment, and we have shown the shortcomings of both the dominant consumer welfare approach and the less accepted inclusive welfare approach in doing so. We have proposed the capability approach as an alternative and have explored what an application of this approach to competition cases might entail. In all of the cases discussed above, when applying a capability approach a balancing act is still necessary to come to a conclusion on whether or not to allow the agreement at issue under a competition law assessment. We have not undertaking that balancing exercise to conclusion but have wanted to show how the capability approach leads to different result from the welfare standards, by introducing three types of relevant capabilities. This shows that the capability approach (i) values market freedom, i.e. the capabilities to property and contract directly; (ii) recognizes consumers' capabilities but limits their value when consumer budgets are above specified thresholds; (iii) can incorporate a wide range of third-party capabilities. As a result, where consumer capabilities are already securely above a certain threshold, they may be outweighed by the value of the capabilities of future generations, the capability to health of current generations, or even by animal capabilities. Whether this

\footnotetext{
${ }^{61}$ H.S. Richardson, "The Stupidity of The Cost-Benefit Standard", Journal of Legal Studies 2000, XXIX, p. 9711003.
} 
is the case, is for producers to argue in the public sphere when they defend their agreements; for competition authorities to assess; and for parliaments to legislate upon when they are unsatisfied with the conclusions that competition authorities reach. 